\title{
Accidental poisoning in young children
}

\author{
D. S. BASA VARAJ \\ From the Durham Area Health Authority, Durham \\ D. P. FORSTER \\ From the Department of Family and Community Medicine, University of Newcastle upon Tyne
}

SUMMARY Cases of accidental childhood poisoning admitted to hospital were compared with community controls and hospital controls matched for age and sex. The relative risks of factors in the cases compared with both the control groups were significant for roughness, aggressiveness, noisiness, and pica behaviour in the child, and for large families. Mothers' knowledge of the toxicity of common household products and drugs did not give significant risk differences between cases and controls. The majority of poisonings occurred during the summer months.

Mortality in England and Wales from accidental poisoning (ICD E850-929) in children aged 0-4 fell only marginally from 4.5 deaths per million in 1968 to 4.0 deaths per million in $1977 .{ }^{12}$ Morbidity, estimated by hospital discharges in this age group for the adverse effects of chemical substances (medicinal and non-medicinal) showed, with minor fluctuations, a rise from 48.7 discharges per 10000 in 1968 to $67 \cdot 1$ per 10000 in $1976 .{ }^{3}$ However, between 1975 and 1976 the discharge rates for medicinal poisonings declined whereas those for non-medicinal poisonings increased. ${ }^{4}$ It remains to be seen how these trends develop. McLean has suggested that, since the length of hospital stay for accidental poisoning in children has fallen, admissions in recent years have been of a more precautionary nature. ${ }^{4}$

Since 1 January 1976, all aspirin and paracetamol for children has had to be dispensed in child-resistant containers or enclosed in dark tinted or opaque unit packaging. Since 1976 most pharmacists have also voluntarily put all dispensed preparations containing aspirin and paracetamol in reclosable child-resistant containers. More recently, dispensed medicines and counter sales of medicines have had to be labelled 'Keep out of the reach of children' or with words of similar meaning. Since March 1981, the voluntary scheme has been extended so that all solid-dose oral preparations are now dispensed in child-resistant containers. $^{5}$

Previous studies, carried out at different times and in different places, have investigated four main categories of potential aetiological factors. Sibert, in Cardiff, suggested that there was more stress in families of children accidentally poisoned than in controls. ${ }^{6}$ Other studies have shown that the personality and behavioural characteristics of children are important factors in accidental poisoning. ${ }^{7-9}$ In the USA it has also been shown that accidental poisoning is not associated with increased availability and accessibility of potentially poisonous substances in the home. ${ }^{1011}$ Furthermore, the American experience is that there is no difference between poisoned cases and controls in their mothers' knowledge of the toxicity of medicines and common household products. ${ }^{11}$ The purpose of the present study was to examine these risk factors as comprehensively as possible in the same population.

\section{Method}

The cases studied were children aged $0-4$ admitted with accidental poisoning to Dryburn Hospital, Durham, and Bishop Auckland General Hospital between July 1978 and September 1979. Accidental poisoning was defined as the accidental ingestion of potentially toxic medicines or household and other products, though the swallowing of indigestible solid items and exposure to noxious gases were excluded. Two controls, matched for age and sex, were selected for each case. A community control was chosen from the health visitor's list of children under 5 from the 
same general practice as the case. A hospital control was chosen from the next appropriate child admitted as an emergency after the accidental poisoning. No children with a history of accidental poisoning were chosen as controls.

The parents of each case and of relevant controls were interviewed at home, usually within one week of the poisoning for cases and within two weeks for controls. The interview included recording a narrative of the poisoning incident in cases. Both cases and controls were given a structured questionnaire at interview, and the questionnaire included inquiries about basic demographic and social data. The child was rated for motor development using the Denver Developmental Screening Test and each child's personality was rated by the mother for 19 items using a seven-point semantic differential for every item. ${ }^{9}$ Parents were specifically asked about the presence of the following symptoms or behavioural characteristics: nightmares or night terrors, nocturnal enuresis, stammering, thumb-sucking, dummy-sucking, nail-biting, recent abnormal eating habits, and recent onset of behavioural problems. In addition, the interview concentrated on certain family stress factors. These were: serious illness or bereavement within the family or among close relations; mother pregnant; single-parent household, or one parent away from home; recently moved house; anxiety or depression in parents; a working mother; and another child under one year old in the home. All mothers were given a toxicology inventory in which they were required to state whether 10 different products in specified amounts were poisonous or non-poisonous for a child aged 3 . The products listed were hair shampoo, cigarettes, aspirins, contraceptive pills, turpentine substitute, laburnum seeds, gripe water, Benylin, Domestos, and Diazepam tablets. The mothers were separated into three groups according to their degree of caution compared with the views of three consultant paediatricians who agreed that six of the 10 products in the toxicology inventory should be considered as poisonous. Finally, inquiries were made about where prescribed and over-the-counter drugs and potentially poisonous household products were kept in the house. The houses were inspected and the drugs and household products were defined as accessible or inaccessible to a child aged 30 months according to defined, standardised criteria. All observations and interviews were carried out by one author (DSB). For individual characteristics the relative risk between cases and both control groups was calculated using McNemar's test. ${ }^{12}$

\section{Results}

One hundred and twelve children aged $0-4$ were admitted to the two hospitals with suspected accidental poisoning during the study period. Seventy-one $(63 \cdot 4 \%)$ were boys, $100(89 \cdot 3 \%)$ were aged 12-47 months, $10(8.9 \%)$ were poisoned by drugs dispensed in childproof containers, $51(45 \cdot 5 \%)$ by other drugs, and $51(45.5 \%)$ by household and other products. The rate of admission during the summer months (July-September), adjusted for the number of days at risk, was almost double that in other periods.

One hundred and six of the poisoned children were admitted to the case-control study; the remaining six were refusals. All 106 cases were matched with community controls and 103 cases with suitable hospital controls. The parents of five initially selected community controls and nine hospital controls refused to take part in the study and each was replaced by the next appropriate control. In both cases and controls, the acceptors and refusers did not differ significantly with respect to sex, social class, or family size.

Table 1 shows a comparison of the mother's assessment of the child's personality characteristics on a seven-point bi-polar scale between cases and both control groups. The cases were assessed as being at significantly greater risk than both control groups in terms of being rougher, noisier, more aggressive, and having a greater tendency to pica.

Table 1 Mother's assessment of child's personality

\begin{tabular}{|c|c|c|c|}
\hline \multirow[b]{2}{*}{ Personality characteristic } & \multicolumn{3}{|c|}{ Mean score } \\
\hline & Cases & $\begin{array}{l}\text { Community } \\
\text { controls }\end{array}$ & $\begin{array}{l}\text { Hospital } \\
\text { controls }\end{array}$ \\
\hline (1) Delicate - Tough & $5 \cdot 34$ & $5 \cdot 02$ & $+\cdot 76^{* *}$ \\
\hline (2) Choosy - Eating well & $5 \cdot 03$ & $4 \cdot 87$ & 4.97 \\
\hline (3) Gentle-Rough & $5 \cdot 39$ & $4 \cdot 50^{* * *}$ & $4 \cdot 66^{* *}$ \\
\hline (4) Timid-Confident & $5 \cdot 06$ & $4 \cdot 99$ & $4 \cdot 84$ \\
\hline (5) Anxious - Relaxed & $5 \cdot 17$ & $5 \cdot 26$ & $4 \cdot 56^{* *}$ \\
\hline (6) Quiet - Noisy & 5.93 & $5 \cdot 35^{* *}$ & $5 \cdot 38^{* *}$ \\
\hline (7) Unhappy - Happy & 6.48 & 6.49 & 6.43 \\
\hline (8) Insecure-Secure & $5 \cdot 65$ & $6 \cdot 15^{* * *}$ & $5 \cdot 27$ \\
\hline (9) Dependent - Independent & $5 \cdot 29$ & $5 \cdot 40$ & $4 \cdot 71^{* *}$ \\
\hline (10) Bad-Good & 4.93 & $5 \cdot 10$ & $5 \cdot 56^{* * *}$ \\
\hline (11) Excitable - Calm & $3 \cdot 70$ & $4 \cdot 10$ & 4.09 \\
\hline (12) Weak - Strong & $5 \cdot 72$ & 5.65 & $4 \cdot 73^{* * *}$ \\
\hline (13) Submissive - Aggressive & $4 \cdot 79$ & $4 \cdot 38^{*}$ & $4 \cdot 39^{*}$ \\
\hline (14) Passive - Active & $6 \cdot 28$ & $6 \cdot 25$ & $5 \cdot 68^{* *}$ \\
\hline (15) Isolated-Sociable & $5 \cdot 85$ & $5 \cdot 83$ & $5 \cdot 32^{* *}$ \\
\hline (16) Selfish-Generous & $4 \cdot 84$ & $5 \cdot 03$ & $4 \cdot 66$ \\
\hline (17) Puts things other than food & & & $5.67^{* * * *}$ \\
\hline $\begin{array}{l}\text { in the mouth - Does not } \\
\text { (18) Not adventurous- }\end{array}$ & $3 \cdot 76$ & $5 \cdot 08^{* * *}$ & $5.6 \%$ \\
\hline Adventurous & $5 \cdot 87$ & $5 \cdot 89$ & $5 \cdot 33^{* *}$ \\
\hline (19) Soft - Hard & $4 \cdot 57$ & $4 \cdot 54$ & $3 \cdot 98^{* *}$ \\
\hline
\end{tabular}

* $p<0.05$

$\left.\begin{array}{l}* * \begin{array}{l}p<0.01 \\ p<0.001\end{array}\end{array}\right\}$ Paired t-test 
Table 2 shows the relative risk between cases and controls for social, environmental, and developmental factors. The relative risks are high and significant compared with both control groups only for large families, that is, those with four or more children. There was no increased risk associated with social class, unemployment, or inadequate accommodation (rated on defined criteria of bedroom availability for family size and pattern).

Table 2 Social, environmental, and developmental factors

\begin{tabular}{|c|c|c|}
\hline \multirow[b]{2}{*}{ Risk factor } & \multicolumn{2}{|l|}{ Relative risk } \\
\hline & $\begin{array}{l}\text { Cases and } \\
\text { community } \\
\text { controls }\end{array}$ & $\begin{array}{l}\text { Cases and } \\
\text { hospital } \\
\text { controls }\end{array}$ \\
\hline Guardian other than natural father & $1 \cdot 8$ & $4 \cdot 7^{* *}$ \\
\hline Four or more children in family & $6 \cdot 0^{* *}$ & $6 \cdot 7^{* * *}$ \\
\hline Regular care by other adults & 0.9 & 0.8 \\
\hline $\begin{array}{l}\text { Poor standard of child care } \\
\text { (Health visitor rating) }\end{array}$ & $4 \cdot 0^{*}$ & 0.8 \\
\hline On observation register & $1 \cdot 0$ & $0.4^{*}$ \\
\hline Below normal development (Denver) & 1.6 & $3 \cdot 0^{*}$ \\
\hline Manual occupation & 0.6 & $1 \cdot 5$ \\
\hline Unemployed head of household & $3 \cdot 0$ & 0.8 \\
\hline Inadequate accommodation & $2 \cdot 3$ & 1.7 \\
\hline Presence of locked medicine cabinet & 0.9 & 1.4 \\
\hline
\end{tabular}

* $p<0.05$

$\because p<0.01\}$ McNemar's test

$* * * \mathrm{p}<0.001$

Specific inquiry about emotional problems or behavioural problems did not give significant relative risks compared with either of the control groups. Family stress factors did not give significant relative risks compared with either control group except for single-parent families in community controls alone $(p<0.05)$ (Table 3). Similarly, there was no significant difference in the proportion of cases or controls with any one or more of these family risk factors.

There was no significant difference between cases and controls in the mothers' accuracy in defining 10

Table 3 Family stress factors

\begin{tabular}{lll}
\hline & \multicolumn{2}{l}{ Relative risk } \\
\cline { 2 - 3 } & $\begin{array}{l}\text { Cases and } \\
\text { community } \\
\text { controls }\end{array}$ & $\begin{array}{l}\text { Cases and } \\
\text { hospital } \\
\text { controls }\end{array}$ \\
\hline Sisk factor & $3.0^{*}$ & 0.8 \\
$\begin{array}{l}\text { Serious illness or bereavement } \\
\text { with family or close relations }\end{array}$ & 1.4 & 0.8 \\
$\begin{array}{l}\text { Mother pregnant } \\
\text { Moved house }\end{array}$ & 1.0 & 1.8 \\
$\begin{array}{l}\text { One parent away from home } \\
\text { Recent onset of anxiety/depression } \\
\text { in parents/guardians }\end{array}$ & 1.2 & 1.2 \\
$\begin{array}{l}\text { Another child in family aged } \\
\text { under one year }\end{array}$ & 1.6 & 0.6 \\
Working mother & 0.9 & 1.4 \\
\hline
\end{tabular}

* $\mathrm{p}<0.05$ McNemar's test stated items as poisonous or not. Further analysis also showed that cases did not differ significantly from controls in the readiness with which they defined items as poisonous. In addition, inspection of the homes showed no significant difference in the risks between cases and controls for the presence of a locked medicine cabinet.

\section{Discussion}

In the mother's assessment of her child's personality and behaviour, our findings agree with Sibert and Newcombe ${ }^{9}$ with respect to putting things other than food in the mouth, although the cluster of traits represented by noisiness, aggressiveness, and roughness are also significantly associated with the cases. Being a child in a family of four or more children was a factor significantly associated with the cases, whereas other social and environmental factors did not give significant differences between cases and either of the control groups. This study failed to support the views of Sibert ${ }^{6}$ in that family stress was not found to be an important factor, although the two studies were carried out in different areas. Family stress requires further investigation.

There is support from this study for the findings in the USA ${ }^{11}$ that parental knowledge of the potential toxicity of medicines and household products is not important, nor indeed is the apparent degree of parental caution in assessing the need for medical care. Although American experience suggests that availability and accessibility of potentially poisonous substances in the home is not associated with accidental poisoning, ${ }^{10}{ }^{11}$ the relative availability and accessibility of drugs and household products could not be evaluated with accuracy in this study because the offending agent had been removed from the homes of the cases at the time of interview.

The preponderance of cases during the summer months, the high relative risks of large families, and the rougher, more aggressive child personalities and pica suggest that it is supervision which is most important in childhood poisoning, although it should be emphasised that this study is concerned with suspected poisoning rather than true poisoning per se. Case-control studies give relative risks, and further longitudinal studies would be required to determine the attributable risk, although it may be prudent for health visitors to advise families with the above risk characteristics about the need for more careful supervision during the summer months.

We thank Dr. J. M. Stansfeld, Dr. J. D. Andrew, and Dr. R. S. Goldberg for allowing their patients to be studied; ward staff and health visitors; Mr. A. McNay 
for computer analysis; and Mrs. Dawn Robinson for secretarial assistance.

Present address of Dr. D. S. Basavaraj: Dorset Area Health Authority.

Reprints from Dr. D. P. Forster, Department of Family and Community Medicine, University of Newcastle upon Tyne, Newcastle upon Tyne NE1 7RU.

\section{References}

${ }^{1}$ Registrar General. Statistical review of England and Wales for 1968, Part 1 (A). London: HMSO, 1970.

${ }^{2}$ Office of Population Censuses and Surveys. Mortality statistics. Accidents and violence for 1977, Series DH4. London: HMSO, 1979.

${ }^{3}$ Department of Health and Social Security. Hospital In-Patient Enquiry for years 1968-1976. London: HMSO, 1972-80.
${ }^{4}$ McLean W. Child poisoning in England and Wales: Some statistics on admissions to hospital, 1964-76. Health Trends 1980; 12: 9-12.

${ }^{5}$ Department of Health and Social Security. Health Notice $H N(F P)(81) 7$. Family Practitioner Services: Safety of Medicines-use of child-resistant containers. London: DHSS, 1981.

${ }^{6}$ Sibert JR. Stress in the families of children who have ingested poisons. $\mathrm{Br}$ Med J 1975; iii: 87-9.

${ }^{7}$ Wehrle PF, de Freest L, Penhollow J, Harris VG. The epidemiology of accidental poisoning in an urban population. III The repeater problem in accidental poisoning. Pediatrics 1961; 27: 614-20.

${ }^{8}$ Okasha A, Bishry Z, Osman NM, Kamel J. A psychological study of accidental poisoning in Egyptian children. Br J Psychiatry 1976; 129: 539-43.

${ }^{9}$ Sibert JR, Newcombe RG. Accidental ingestion of poisons and child personality. Postgraduate Medical Journal 1977; 53: 254-6.

${ }^{10}$ Sobel R. Traditional safety measures and accidental poisoning in childhood. Pediatrics 1969; 44: 811-6.

${ }^{11}$ Baltimore C jr, Roger J, Meyer J. A study of storage, child behavioural traits and mothers' knowledge of toxicology in 52 poisoned families and 52 comparison families. Pediatrics 1969; 44: 816-20.

${ }^{12}$ Lilienfield AM. Foundations of epidemiology. New York: Oxford University Press, 1976: 180-1. 